\title{
Motivational Field of Creative Activities of the Population of the South of Russia Based on the Materials of Research in the Stavropol Territory
}

\author{
Valentina Anatolyevna Ivashova ${ }^{1 *}$, Yuliya Borisovna Nadtochy ${ }^{2}$, Lidia Sergeevna Budovich $^{3}$, Evgeniya \\ Valeryevna Volobuyeva ${ }^{4}$, Natalia Mikhailovna Volkova ${ }^{5}$ \\ ${ }^{1}$ Stavropol State Agrarian University, Zootechnical per. 12, Stavropol, 355017, Russia \\ ${ }^{2}$ Institute of Economics and Law, MIREA - Russian Technological University (RTU MIREA), Stromynka str., 20, Moscow, 107996, \\ Russia \\ ${ }^{3}$ Institute of Economics and Law, MIREA - Russian Technological University (RTU MIREA), Stromynka str., 20, Moscow, 107996, \\ Russia \\ ${ }^{4}$ Stavropol State Pedagogical Institute, Zootechnical per. 12, Stavropol, 355017, Russia \\ ${ }^{5}$ Institute of Economics and Law, MIREA - Russian Technological University (RTU MIREA), Stromynka str., 20, Moscow, 107996, \\ Russia \\ *Corresponding author E-mail: vivashov@mail.ru
}

\begin{abstract}
The article considers the results of study of the motivational field, ensuring the participation of the population of the Stavropol Territory in amateur arts. The analysis of factors and conditions that contribute to the involvement of residents of the South of Russia in the creative activity on the basis of branch organizations of culture. The motivational sphere of professional activities of the heads of amateur groups of artistic creativity is considered as an important factor ensuring stable reproduction of positive social practices aimed at preserving the original cultural environment of the strategically important region of Russia.

The study found that the stability of the composition of groups with a tendency to rejuvenation of participants is maintained; the main motive for citizens is the desire to engage in creativity (stated by every second participant of the survey), such motives as the desire to be seen, the ability to communicate, the impression of visiting the concert are also significant; the attractiveness of classes in the team of amateur arts is provided by active concert activities, the opportunity to speak to the public, regular rehearsal activities, cultural leisure, communication with people, spiritual growth and the opportunity to escape from everyday worries.
\end{abstract}

Keywords: motivational field, amateur artistic creativity, cultural activities, population.

\section{Problem Statement}

One of the important areas of work of the Ministry of culture of the Russian Federation is to ensure the conditions for the development of amateur artistic creativity of the population, which plays an important role in the system of preservation of national cultural values, cultural leisure of the population of Russia. [1, 2, 3]

Institutionally, this is done through the involvement of the population to participate in the activities of amateur groups operating on the basis of sectoral cultural organizations. Therefore, it is important to analyze trends in the development of the motivational sphere of participants and leaders of these groups and the conditions that ensure the stability and stability of the motivational field, which is understood as the living space of a person as a set of interrelated facts. They determine the behavior of a person in a particular situation at a given time. These may be expectations, goals, images of attractive (or repulsive) objects, real or imagined obstacles to achieve the desired, human activity, etc. $[4,5,7,8,10]$

\section{Analysis of Previous Studies}

Modern studies of foreign authors confirm the relevance of the topic and selected research methods. $[9,13]$

In their book the Dynamic Force Before Intrinsic Motivation: Exploring Creative Needs Luria, S. R., Kaufman, J. C. consider the issue of motivation and creativity from the standpoint of external and internal motivation. The urgency of the issue of the ways to support someone's internal motivation to certain activities is emphasized. There is a discussion of the concept of creative needs, which is considered by the authors as a fusion of values, interests and passion. Based on the interviews, 6 potential creative needs were identified: beauty, strength, openness, communication, individuality and pleasure. [6] 
The research work of Stanko-Kaczmarek, M. the Effect of Intrinsic Motivation on the Affect and Evaluation of the Creative Process Among Fine Arts Students, published in the Creativity Research Journal (2012), is important to understand the impact of internal motivation on the subjective assessment and creative process of people, on the example of young artists. The author considers the relationship between motivation, impact and evaluation of the creative process as a dynamic one. The unique contribution of this research is that it considers not only the influence of internal motivation on the final result of creativity, but also changes in the subjective evaluation and the impact of intermediate results on the outcome of the creative process. [11] The research work of Ruokonen, I., Koala, K., Mail da, M., Vika, M., Ruismäki, H. Creative catalysts in university students learning environments emphasizes the relevance of determining the factors becoming catalysts for the development of artistic talent of an individual. The following factors were highlighted among the key ones: the immediate environment of the person at home, at school, especially culture, community, hobbies, as well as gender and random impact. The researchers used a qualitative method of analysis. The results of the analysis showed that various incentives in the educational environment play an important role in the development of the talent and creativity. The combination of home and school environment factors, cultural communities and the possibility of non-formal education of creative activities were necessary for the development of their talent. [12]

Studies by Gelade, G. A. Creative style, personality, and artistic endeavor have shown that the creative style measured by Kirton's Innovative Stock (KAI, MJ Kirton, 1976) correlates with more than 30 different personality traits. In this article, the author demonstrates that many of these correlations can be understood within the framework of the five-factor model of personality and shows that the prevailing correlates of creative style are indicators of personality in the areas of factors of integrity, openness to experience, and, to a lesser extent, extroversion. These results provide a basis for comparing the personal qualities associated with creative style and professional creativity. [18]

Overall research strategy of motivation of creative activities varied. Scientists use both qualitative and quantitative methods of research of factors of the involvement of a person in creative activities. Factors of motivation of creative activities are structured according to different grounds. There are internal and external motivation for creativity, the so-called environmental factors of motivation (the nearest environment of a person). In addition, the creative style of the person is determined by the indicators: honesty, openness to experience, and, to a lesser extent, extroversion. [15, 16, ]

The purpose of the presented research work: to conduct a sociological analysis of the motivational field, ensuring the involvement of the population in the work of amateur art groups on the example of one of the regions of the South of Russia.

\section{Materials and Methods}

In June-September, 2017 a survey of heads and members of amateur art groups in the Stavropol Territory was conducted. A total of 136 managers and 296 participants of amateur art groups took part in the survey. The research tools were developed separately for managers and participants of creative associations. The replies of the respondents reveal the motivational field of professional activity and social well-being of the heads of amateur art groups and give an idea of the main motives of the population's participation in the work of creative teams. The study presents comparative data of surveys of previous years on the invariant part of the tools.

\section{Presentation of the Main Research Materials}

Before moving on to the content characteristic of the motivational field, we are to consider how constant this type of cultural activity is for the participants of creative teams.

According to the results of a survey of participants of amateur art groups from among the population of the Stavropol Territory, we can outline that in general, against the background of the relative stability of the groups, there is some rejuvenation of their teams. The data are presented in table 1.

Table 1: Distribution of replies to the question: "How long have you been involved in this amateur group?", \%

\begin{tabular}{|l|l|l|l|l|}
\hline No. & \multicolumn{1}{|c|}{ Answers } & $\mathbf{2 0 0 8}$ & $\mathbf{2 0 1 4}$ & \multicolumn{1}{|c|}{017} \\
\hline 1. & Less than one year & 8,5 & 9,5 & 7,9 \\
\hline 2. & From one to three years & 27,7 & 24,2 & 31,6 \\
\hline 3. & From three to five years & 16,9 & 16,8 & 26,0 \\
\hline 4. & From five to ten years & 16,2 & 31,6 & 12,3 \\
\hline 5. & From ten to twenty years & 14,6 & 10,5 & 10,0 \\
\hline 6. & For over twenty years & 16,2 & 7,4 & 6,9 \\
\hline
\end{tabular}

Thus, the share of participants who have been in the teams for more than 20 years has decreased from $16.2 \%$ in 2008 to $6.9 \%$ in 2017, while the share of participants involved in the teams from 1 to 5 years has increased significantly - from $44.6 \%$ in 2008 to $57.6 \%$ in 2017 .

Among the reasons that prompted citizens to turn to amateur artistic creativity in the first place - the desire to engage in creativity (noted $54.0 \%$ of respondents in 2017). Other reasons are much less significant. Among them: the need for communication (noted by $19.8 \%$ of respondents in 2017); attending a concert, an exhibition (noted by $10.1 \%$ of respondents in 2017 ); the desire to be seen (noted by $8.6 \%$ of respondents in 2017 ); dynasty (noted by $4.9 \%$ of respondents in 2017).

Respondents from among the participants of amateur art groups note the regularity of performances of groups with creative concerts, performances, exhibitions, which are held for the solemn and festive dates $(56.6 \%)$, almost once a month $(25.3 \%)$, several times a year $(17.7 \%)$. Only $0.3 \%$ of respondents noted very rare performances. The data are presented in table 2 .

Table 2: Distribution of replies to the question: "How often do you represent the results of your work (concert, performance, exhibition) to the audience?" \%

\begin{tabular}{|l|l|l|l|l|}
\hline No. & \multicolumn{1}{|c|}{ Answers } & 2008 & 2014 & 2017 \\
\hline 1. & By the solemn, festive dates & 58,1 & 46,7 & 56,6 \\
\hline 2. & Almost 1 time per month & 34,9 & 28,3 & 25,3 \\
\hline 3. & Several times a year & 17,1 & 16,3 & 17,7 \\
\hline 4. & Very rarely & 2,3 & 2,2 & 0,3 \\
\hline 5. & Other & 8,3 & 6,5 & - \\
\hline
\end{tabular}

In most cases (about 95.3 per cent) of the members of the group have their full responsibility regarding the performances, and, in the opinion of $6.6 \%$, it significantly increases during performances at contests and with a large audience. In this case, the degree of responsibility is directly proportional to the level of excitement experienced by participants before the performance.

The vast majority of participants (about 97.5\%) attend them free of charge; however, every fourth respondent noted that the audience must be charged a certain fee.

For many years, the teams have had a consistently good psychological microclimate. According to the five-point scale of the relationship in the team, the participants are estimated at 4.9 points, the team with the head-at 4.9 points, the team with the administration of a club - at 4.8 points.

A significant role in the motivation of citizens ' participation in the creative activities of the team is given to the possibility of public perfomances. In order to demonstrate the concert shows adequately, good concert costumes are needed. Currently, the problem of costumes is not solved in about a fifth of the teams. The proof of the existence of such a problem is the fact of purchase and renewal of costumes at the expense of the 
participants of the groups (noted by $10.6 \%$ of the number of respondents) and performances in their own clothes (noted by $9.6 \%$ of the number of respondents). A more significant contribution to the solution of this problem is made by local municipalities, however, according to the estimates of participants of various teams the regional budget does not participate in the financing of the renewal of costumes.

In order to sustain a high motivation of the population's participation in the work of creative teams, thereby steadily reproduce positive social practices; preserve the national culture and identity of such a strategically important region as the South of Russia, successful work of heads of creative teams is highly important. Therefore, it is vital to understand the motivational field of professional activities and social well-being of leaders of amateur artistic creativity groups.

The most highly appreciated in the choice of the sphere of professional activities of the leaders of amateur artistic groups is the fact that they enjoy what they are doing ( 76.2 per cent). Other answers were chosen by a much smaller number of survey participants: work provides material benefits $(9.2 \%)$, makes it possible to be in the midst of social life $(7.7 \%)$ and mobilizes to constantly work on themselves $(7.0 \%)$.

With a relatively high level of demand for employment in amateur art groups-56.1\% (in 2008, this figure was estimated by managers $56.3 \%$, in $2014-62.2 \%$ ) according to the survey participants, the profession of a club worker is valued in society is not very highly - $54.5 \%$, low $-9.0 \%$, very low $-5.2 \%$, another $4.5 \%$ of respondents found it difficult to give a certain reply. The high status of the profession of a club employee was noted by $23.1 \%$ of leaders of amateur artistic groups and very high at $3.7 \%$ of survey participants. The data are presented in table 3 .

Table 3: Distribution of replies to the question: "How high do you think the profession of a club worker is evaluated?", $\%$

\begin{tabular}{|l|l|l|l|l|}
\hline No. & Types of replies & 2008 & 2014 & 2017 \\
\hline 1. & Very highly & 3,1 & - & 3,7 \\
\hline 2. & Highly & 6,2 & 18,9 & 23,1 \\
\hline 3. & Not very highly & 44,6 & 48,6 & 54,5 \\
\hline 4. & Low & 27,7 & 13,5 & 9,0 \\
\hline 5. & Very low & 10,8 & 10,8 & 5,2 \\
\hline 6. & Hard to reply & 7,7 & 8,1 & 4,5 \\
\hline
\end{tabular}

The leaders of amateur art groups themselves express complete satisfaction with their work as a whole, with $31.1 \%$ noting that they cannot imagine themselves without their work.

The ranking of factors influencing the high level of job satisfaction, shows that the first place refers to the positive attitude of others to the work in the club $(87.7 \%)$; the second place refers to the positive attitude towards employees from the head of a club, Department of culture $(85.5 \%)$; the third place refers to the content of work that is performed by the heads of amateur art groups $(80.2 \%)$.

One of the main conditions affecting the success of the professional activity is the material remuneration for work. In the survey of 2017, the share of heads of amateur art groups, who attributed their family to the group of wealthy and rather wealthy than not, amounted to $53 \%$. However, 43.4 per cent of the respondents identified themselves as poor. And $3.6 \%$ of the survey participants could not definitively answer this question.

\section{Discussion and Conclusions}

Describing the motivation of the population's participation in the work of amateur art groups in general, the following positive trends can be identified in recent years:

- Stability of the composition of teams with a tendency to rejuvenate the participants;

- the main motive of citizens to turn to amateur artistic creativity is the desire to be engaged in creativity (noted by every second participant of the survey), the following motives as the desire to be in sight, the ability to communicate, the impression of attending the concert were also stated as significant;

- the attractiveness of classes in the team of amateur art is provided by active concert activities, the opportunity to speak to the public, regular rehearsal activities, cultural leisure, communication with people, spiritual growth and the opportunity to escape from everyday worries.

For many years, the teams have had a consistently good psychological microclimate. According to the five-point scale of the relationship in the team, the participants estimated it at 4.9 points, the one of the team with their leader-at 4.9 points, the one of the team with a club's administration - at 4.8 points.

A significant role in maintaining a high motivation for the public participation in the creative activities of the team is given to the opportunity of public perfomances. In order to demonstrate the concert perfomances adequately, good concert costumes are necessary. Currently, the problem of costumes is not solved in about $20 \%$ of the teams. Confirmation of the reality of such a problem is the facts of the acquisition and renewal of costumes at the expense of members of the teams (noted $12.3 \%$ of the number of respondents).

At the same time, the leaders of amateur art groups expressed their opinion that the participation in the amateur artistic creativity has a positive impact on the formation of such qualities as aesthetic artistic taste, creativity, looseness and freedom of expression.

\section{Recommendations and Prospects of Research}

The information obtained in the course of the research is important to understand the motivational field of the participants of amateur art groups. In turn, this information is vital to determine the program goals and activities for the implementation of the cultural policy of the Stavropol Territory and the South of Russia, the stability of the cultural structure of the region. [14, 17, 19]

The continuation of monitoring studies of the motivational field of employment of the population with amateur artistic creativity will provide an information base for the analysis of social and cultural processes in the regional community of the Stavropol Territory and the entire South of Russia.

\section{References}

[1] N.A. Thompson, Imagination and Creativity in Organizations, Organization Studies 39(2-3) (2018) 229-250.

[2] Z. Geng, C. Li, K. Bi, et al., Motivating service employee creativity: regulatory focus and emotional labour, Journal of Service Theory and Practice 28(2) (2018) 228-249.

[3] Yu.B. Nadtochii, L.S. Budovich, Intellektual'nyj kapital organizacii: sushhnost', struktura, podhody $\mathrm{k}$ ocenke [The intellectual capital of the organization: the essence, structure, approaches to evaluation], Rossijskij tehnologicheskij zhurnal (jelektronnoe setevoe izdanie). 6(2) (2018) 82-95.

[4] K. Arun, S. Sudha, Explorating employee creativity as a driver to empower employees in hospitality industry, Indian Journal of Public Health Research and Development 8(4) (2017) 313-318.

[5] W. Mihret Dessie, A. Shumetie Ademe, Training for creativity and innovation in small enterprises in Ethiopia, International Journal of Training and Development 21(3) (2017) 224-234.

[6] S.R. Luria, J.C. Kaufman, The Dynamic Force Before Intrinsic Motivation: Exploring Creative Needs, The Creative Self: Effect of Beliefs, Self-Efficacy, Mindset, and Identity, Elsevier Academic Press, San Diego, 2017, 317-325.

[7] S. Zahro, M.C. Wu, N. Hidayati, et al., Employees' creativity development in Indonesia's fashion sub-sectors, Human Systems Management 36(1) (2017) 27-39.

[8] N.G. Khairullina, V.A. Garabagiu, I.A. Filippova, et al., Research of creative activity among students of Tyumen's universities, Espacios, 38(25) (2017) 24

[9] D.W. Zaidel, Creativity, brain, and art: Biological and neurological considerations, Frontiers in Human Neuroscience 8(06) (2014) 389. 
[10] M. Musial, A. Kauppinen, V. Puhakka, Recognised creativity: The influence of process, social needs, and the third drive on creative individuals' work through social media, Cutting-Edge Technologies and Social Media Use in Higher Education, IGI Global, Hershey, 2014, 242-273.

[11] M. Stanko-Kaczmarek, The Effect of Intrinsic Motivation on the Affect and Evaluation of the Creative Process Among Fine Arts Students, Creativity Research Journal 24(4) (2012) 304-310.

[12] I. Ruokonen, K. Kiilu, M. Muldma, et al., Creative catalysts in university students' learning environments, Procedia - Social and Behavioral Sciences 29 (2012) 412-421.

[13] S.G. Shamay-Tsoory, N. Adler, J. Aharon-Peretz, et al., The origins of originality: The neural bases of creative thinking and originality, Neuropsychologia 49(2) (2011) 178-185.

[14] Y. Kowatari, S. Hee Lee, H. Yamamura, et al., Neural networks involved in artistic creativity, Human Brain Mapping 30(5) (2009) 1678-1690.

[15] N.E. Perrine, R. Marc Brodersen, Artistic and scientific creative behavior: Openness and the mediating role of interests, Journal of Creative Behavior 39(4) (2005) 217-236.

[16] R.A. Chávez, A. Graff-Guerrero, J.C. García-Reyna, et al., Neurobiology of creativity: Preliminary results from a brain activation study | [Neurobiología de la creatividad: Resultados preliminares de un estudio de activación cerebral], Salud Mental 27(3) (2004) 38-46.

[17] N. LeBoutillier, D.F. Marks, Mental imagery and creativity: A meta-analytic review study, British Journal of Psychology 94(1) (2003) 29-44

[18] G.A. Gelade, Creative style, personality, and artistic endeavor, Genetic, Social, and General Psychology Monographs 128(3) (2002) 213-234

[19] A.R. Manheim, The Relationship between the Artistic Process and Self-Actualization, Art Therapy 15(2) (1998) 99-106. 